\title{
Intraspinal transplantation of subventricular zone-derived neural progenitor cells improves phrenic motor output after high cervical spinal cord injury
}

\author{
Sandhu $\mathrm{MS}^{1}$, Ross $\mathrm{HH}^{1}$, Lee $\mathrm{KZ}^{1}$, Ormerod $\mathrm{BK}^{3}$, Reier $\mathrm{PJ}^{2}$, Fuller $\mathrm{DD}^{1^{*}}$ \\ ${ }^{1}$ University of Florida, Department of Physical Therapy, P.O. Box 100154, Gainesville, FL \\ 32610-0154 \\ ${ }^{2}$ University of Florida, Department of Neuroscience, P.O. Box 100244, Gainesville, FL 32610- \\ 0244 \\ ${ }^{3}$ University of Florida, Department of Biomedical Engineering, P.O. Box 116131, Gainesville, FL \\ 32611-6131 \\ *, corresponding author \\ ddf@phhp.ufl.edu \\ Phone: (352) 273-6634 \\ Fax: (352) 273-6109
}

Submitted to: Experimental Neurology

Date: May 30, 2016

Running Head: Neural precursor cell transplantation increases respiratory motor output after spinal cord injury 


\section{Abstract}

Following spinal cord injury (SCl), intraspinal transplantation of neural progenitor cells (NPCs) harvested from the forebrain sub-ventricular zone (SVZ) can improve locomotor outcomes. Cervical SCl often results in respiratory-related impairments, and here we used an established model cervical $\mathrm{SCl}$ ( $\mathrm{C} 2$ hemisection, $\mathrm{C} 2 \mathrm{Hx}$ ) to confirm the feasibility of mid-cervical transplantation of SVZ-derived NPCs and the hypothesis that that this procedure would improve spontaneous respiratory motor recovery. NPCs were isolated from the SVZ of enhanced green fluorescent protein (GFP) expressing neonatal rats, and then intraspinally delivered immediately caudal to an acute $\mathrm{C} 2 \mathrm{Hx}$ lesion in adult non-GFP rats. Whole body plethysmography conducted at 4 and 8-wks post-transplant demonstrated increased inspiratory tidal volume in SVZ vs. sham transplants during hypoxic $(P=0.003)$ or hypercapnic respiratory challenge $(P=0.019)$. Phrenic nerve output was assessed at 8-wks post-transplant; burst amplitude recorded ipsilateral to $\mathrm{C} 2 \mathrm{Hx}$ was greater in SVZ vs. sham rats across a wide range of conditions (e.g., quiet breathing through maximal chemoreceptor stimulation; $\mathrm{P}<0.001$ ). Stereological analyses at 8 wks post-injury indicated survival of $\sim 50 \%$ of transplanted NPCs with $\sim 90 \%$ of cells distributed in ipsilateral white matter at or near the injection site. Peak inspiratory phrenic bursting after NPC transplant was positively correlated with the total number of surviving cells $(P<0.001)$. Immunohistochemistry confirmed an astrocytic phenotype in a subset of the transplanted cells with no evidence for neuronal differentiation. We conclude that intraspinal transplantation of SVZ-derived NPCs can improve respiratory recovery following high cervical $\mathrm{SCl}$.

Keywords: phrenic; neural precursor cells; plasticity; astrocyte 


\section{Introduction}

Multiple laboratories have confirmed that transplantation of neural precursor cells (NPCs) into the injured spinal cord can improve motor recovery (Bonner et al., 2011; Fischer, 2000; Mitsui et al., 2005; Reier, 2004; Snyder and Teng, 2012). While there are numerous potential NPC sources (reviewed in (Reier, 2004)), the current investigation focused on cells derived from the forebrain sub-ventricular zone (SVZ). The SVZ contains a robust NPC population that can be harvested and readily expanded in vitro (Alvarez-Buylla et al., 2002), and NPCs derived from the SVZ have been successfully transplanted into the injured spinal cord (Cao et al., 2001; Karimi-Abdolrezaee et al., 2006a; Mligiliche et al., 2005; Oka et al., 2004; Zhang et al., 2009). These spinal cord injury (SCI) studies have generally produced positive outcomes including enhanced myelination at or near lesions (Oka et al., 2004) and improved locomotor function (Karimi-Abdolrezaee et al., 2006b). The transplanted NPCs can develop into both astrocytes (Mligiliche et al., 2005) and oligodendrocytes (Karimi-Abdolrezaee et al., 2006b), but to our knowledge no prior studies show robust neuronal differentiation in the injured spinal cord. Thus, this NPC transplantation approach is not a "neuronal replacement" therapy, and mechanisms including neuroprotection (Llado et al., 2004), immunomodulation (Ziv et al., 2006) and re-myelination (Xing et al., 2014) have been suggested to drive the observed motor recovery. Much of the aforementioned work was cited as the rationale for a recent study of NPC transplantation in humans with cervical SCI (Shin et al., 2015). In that trial, transplantation of human NPCs derived from the fetal telencephalon (a region containing the SVZ) was reported to be safe and well-tolerated by recipients.

Respiratory neuromotor output is always impacted by cervical SCI, and respiratoryrelated impairments are a primary cause of morbidity and mortality. Here, we used an established model of respiratory dysfunction after $\mathrm{SCl}$ (high cervical hemisection, $\mathrm{C} 2 \mathrm{Hx}$ (Goshgarian, 2003) (Sandhu et al., 2009)) to enable a quantitative evaluation of the impact of intraspinal transplantation of SVZ-derived NPCs on respiratory motor recovery. An important 
feature of the $\mathrm{C} 2 \mathrm{Hx}$ model is that post-injury respiratory motor impairments can be readily quantified and interpreted both in anesthetized and unanesthetized animals (Sandhu et al., 2009). In the current study, NPCs were isolated from the SVZ of embryonic green fluorescent protein (GFP) expressing neonatal rats, and then intraspinally delivered immediately caudal to an acute $\mathrm{C} 2 \mathrm{Hx}$ lesion in adult non-GFP expressing rats that were otherwise syngeneic. This approach allowed us to test the hypothesis that high cervical transplantation of SVZ-derived NPCs would improve spontaneous respiratory motor recovery after cervical SCl. A secondary purpose was to histologically evaluate the local migration patterns of the transplanted NPCs, and to examine the differentiation patterns of the cells following transplantation.

\section{Materials and Methods}

Animals

Experiments were conducted using adult female Sprague-Dawley rats (Harlan Inc., Indianapolis, IN, USA) and neonatal Sprague-Dawley rat pups carrying a germline enhanced green fluorescent protein (EGFP) transgene (bred under University of Florida in house breeding protocols). This colony was obtained via material transfer permission from the colony creators at the University of Missouri on behalf of the University of Missouri-Columbia). All procedures were approved by the University of Florida Institutional Animal Care and Use Committee.

\section{NPC harvest and expansion}

NPCs were derived from neonatal EGFP-expressing Sprague Dawley (SD-Tg(GFP)2BalRrrc) rats at postnatal day 4 as previously described (Ross et al., 2012). Brains were removed after rapid decapitation, and tissue blocks containing the SVZ were dissected, incubated for 5 mins in trypsin $(0.05 \%)$, dissociated into single-cell slurry, and plated overnight in growth medium. Growth media consisted of Rat Neurocult base media (Stemcell Technologies Inc., Canada) containing a rat proliferation supplement (Stemcell Technologies Inc., Canada), basic fibroblast 
growth factor [10ng/ml, bFGF], and epidermal growth factor [10ng/ml, EGF]. To isolate neurosphere-forming cells, the non-adherent cell slurry was aspirated after $24 \mathrm{~h}$, pelleted by centrifugation, and incubated in trypsin for $2 \mathrm{~min}$. Cells were gently triturated, washed, resuspended and then plated in non-adherent flasks at clonal density $\left(10,000\right.$ cells $\left./ \mathrm{cm}^{2}\right)$ in growth medium. Cells were expanded in ultra-low attachment plates to promote floating sphere formation (Costar, \#3471). The resultant neurospheres (NS) were passaged 2-3x in the same growth medium. To prepare a cell suspension for delivery into the injured adult spinal cord, NS were mechanically dissociated into single cells during passage, and cell number and viability was assessed using trypan blue exclusion (Ross et al., 2012). An aliquot of the cells prepared for transplant were plated on poly-L-ornithine-coated coverslips and then fixed in $4 \%$ paraformaldehyde for 1 hour at room temperature (RT) and blocked for 1 hour at RT in PBS containing $0.01 \%$ Triton X-100 and 10\% FBS. Primary antibody (rabbit anti-ß-III tubulin 1:200; rabbit anti-glial fibrillary acidic protein (GFAP) 1:2000) was applied overnight at $4^{\circ} \mathrm{C}$. Coverslips were washed $2 \times 10 \mathrm{~min}$ in wash buffer (PBS, 0.01\% Triton X-100) and incubated with fluorescence-conjugated secondary antibody (goat anti-mouse, goat anti-rabbit) for 3h at RT. Slips were washed $2 \times 10 \mathrm{~min}$ in wash buffer, mounted on positively charged glass slides (Fisherbrand Superfrost/Plus, Fisher Scientific, Pittsburg, PA) and cover-slipped in Vectashield containing DAPI counterstain (Vector Laboratories, Burlingame, CA). Fluorescence micrographs were obtained with a Leica DMLB epifluorescence microscope equipped with a color Spot cooled CCD digital camera.

\section{SCl and transplantation}

Experiments were performed in separate cohorts of experimental animals, separated by approximately 6 months. All rats underwent $\mathrm{C} 2 \mathrm{Hx}$ surgery as described below. In the first cohort, $\mathrm{N}=8$ rats had NPC transplant (body weight $=269 \pm 3 \mathrm{~g}$ ), $\mathrm{N}=4$ rats had intraspinal delivery of the growth medium (i.e., sham transplant; body weight $=260 \pm 3 g$ ), and $N=4$ rats received 
$\mathrm{C} 2 \mathrm{Hx}$ only (body weight $=260 \pm 7 \mathrm{~g}$ ). In the second cohort, there were $\mathrm{N}=7 \mathrm{NPC}$ transplants (body weight $=262 \pm 4 \mathrm{~g}$ ) and $\mathrm{N}=3$ sham transplants (body weight $=261 \pm 4 \mathrm{~g}$ ). Qualitatively similar results were obtained in both cohorts of NPC transplants for all outcome variables, and the data were combined in the final presentation of the results. Similarly, no differences were detected in any of the neurophysiological or plethsymography measures (all $P$ values $>0.15$ ) between the groups receiving sham transplant $(\mathrm{N}=7)$ or $\mathrm{C} 2 \mathrm{Hx}$ only $(\mathrm{N}=4)$. Therefore, these animals were combined into a single control group for statistical comparison of functional outcomes with rats receiving NPC transplants. The final cohort of rats $(\mathrm{N}=6$, body weight $=284$ $\pm 5 \mathrm{~g}$ ) received NPC transplantation and were used only for spinal immunohistochemistry experiments.

Prior to SCI, rats were anesthetized with xylazine $(10 \mathrm{mg} / \mathrm{kg} \mathrm{s.q.;} \mathrm{Phoenix} \mathrm{Pharmaceutical,}$ Inc., St. Joseph, MO) and ketamine (120 mg/kg i.p.; Fort Dodge Animal Health, Fort Dodge, IA). The $\mathrm{C} 2 \mathrm{Hx}$ lesion was induced as previously described (Doperalski and Fuller, 2006; Fuller et al., 2008; Lane et al., 2008). Following surgery, an analgesic (buprenorphine, 0.03 mg/kg, s.q.) was given every $12 \mathrm{~h}$ for 2 days, and lactated ringers solution (12 ml/day, s.q.) was provided as needed for 2-4 days. Seven days after $\mathrm{C} 2 \mathrm{Hx}$ surgery, rats were anesthetized again, and the dissociated NPC suspension was delivered intraspinally after surgically exposing the C2-3 spinal cord. A total volume of $5 \mu$, containing approximately 500,000 live cells diluted in growth medium (described above), was injected using a 10 $\mu$ l Hamilton glass syringe and a 31 gauge needle. The tip of the needle was positioned in the ventromedial white matter, approximately $1 \mathrm{~mm}$ caudal to the lesion site and $1.5 \mathrm{~mm}$ from the dorsal surface of the spinal cord. Sham injections consisted of an equal volume of growth medium. All animals received daily injections of cyclosporine A immunosuppressant $(10 \mathrm{mg} / \mathrm{kg}$, s.q., Sandimmune; Novartis, East Hanover, $\mathrm{NJ}$ ) starting two days before transplantation and continuing until the end of the experiment. 


\section{Respiratory outcome measures}

Ventilation was measured in unanesthetized, unrestrained rats using a whole-body plethysmography system (Buxco Inc., Wilmington, NC, USA) as previously described (Fuller et al., 2008). Baseline recordings lasted $1-1.5 \mathrm{~h}$, and were made while the chamber was flushed with $21 \% \mathrm{O}_{2}$ (balance $\mathrm{N}_{2}$ ). Rats were then exposed to two successive respiratory challenges separated by a 5-min normoxic recovery period. First, the chamber was flushed with $10 \% \mathrm{O}_{2}$ (balance $\mathrm{N}_{2}$ ) for 5 min to provide an hypoxic respiratory stimulus. Second, the chamber was flushed with $7 \% \mathrm{CO}_{2}, 21 \% \mathrm{O}_{2}$ mixture (balance $\mathrm{N}_{2}$ ) for an hypercapnic stimulus. Data which were derived from the plethysmograph airflow recordings included inspiratory frequency (breaths per minute), inspiratory tidal volume (mls per breath), inspiratory minute ventilation (mls per minute), peak inspiratory airflow rate $(\mathrm{mls} / \mathrm{sec})$, peak expiratory airflow rate $(\mathrm{mls} / \mathrm{sec})$, inspiratory duration (sec), and expiratory duration (sec). These data were averaged over a 10min period of stable breathing during the final 30-min of the baseline recording, and over the final min of the hypoxic and hypercapnic challenges. Respiratory volume data were expressed in absolute units (i.e., mls), per $100 \mathrm{~g}$ body mass, and also relative to the baseline value.

Phrenic nerve recordings were conducted as previously described (Sandhu et al., 2010). Rats were initially anesthetized with isoflurane $\left(5 \%\right.$ in $\left.100 \% \mathrm{O}_{2}\right)$ and then continued to breath an isoflurane mixture via a nose cone $\left(2-3 \%\right.$ isoflurane in $50 \% \mathrm{O}_{2}$, balance $\left.\mathrm{N}_{2}\right)$ while the trachea was cannulated (PE-240 tubing). After mechanical ventilation was initiated, a catheter (PE-50) was placed in the femoral vein, and isoflurane was withdrawn gradually in parallel with i.v. urethane delivery $(1.6 \mathrm{~g} / \mathrm{kg} ; 0.12 \mathrm{~g} / \mathrm{ml}$ distilled water). A femoral arterial catheter (PE-50) was inserted to measure blood pressure (Statham P-10EZ pressure transducer, CP122 AC/DC strain gage amplifier, Grass Instruments, West Warwick, RI, USA) and to enable withdrawal of blood samples (see protocol). Rats were bilaterally vagotomized to prevent phrenic-ventilator entrainment, and paralyzed with pancuronium bromide $(2.5 \mathrm{mg} / \mathrm{kg}$, i.v. $)$ to eliminate respiratory muscle contraction. An infusion of lactated Ringer's solution and sodium bicarbonate (3:1, 
$1.5 \mathrm{ml} / \mathrm{h}$ ) was maintained to promote acid-base balance (Baker-Herman et al., 2009). Arterial partial pressures of $\mathrm{O}_{2}\left(\mathrm{PaO}_{2}\right)$ and $\mathrm{CO}_{2}\left(\mathrm{PaCO}_{2}\right)$ as well as $\mathrm{pH}$ were determined during baseline, hypoxia and post-hypoxia period from $0.2 \mathrm{ml}$ arterial blood samples using an i-Stat analyzer (Heska, Fort Collins, $\mathrm{CO}$, USA). The end-tidal $\mathrm{CO}_{2}$ partial pressure $\left(\mathrm{PET}_{\mathrm{CO} 2}\right)$ was measured throughout the protocol using a rapidly responding mainstream $\mathrm{CO}_{2}$ analyzer positioned a few cms from the tracheostomy tube on the expired line of the ventilator circuit (Capnogard $\mathrm{CO}_{2}$ monitor, Novametrix Medical Systems, Wallingford, CT, USA). Rectal temperature was maintained at $37 \pm 1{ }^{\circ} \mathrm{C}$ using a rectal thermistor and heating pad (model TC1000, CWE Inc., Ardmore, PA, USA). Electrical activity of both phrenic nerves was recorded using silver wire electrodes, and the signal was amplified (1000x) and filtered (band pass of $300-10,000 \mathrm{~Hz}$, notch filter set at $60 \mathrm{~Hz}$ ) using a differential A/C amplifier (Model 1700, A-M Systems, Carlsborg, WA, USA). The amplified signal was full-wave rectified and moving averaged (time constant 100 ms; model MA-1000; CWE Inc., Ardmore, PA, USA) to create an "integrated" output (JPhr). Data were digitized using a CED Power 1401 data acquisition interface and recorded on a PC using Spike2 software (Cambridge Electronic Design, Cambridge, England).

The phrenic nerve recording protocols was as follows. First, the $\mathrm{PET}_{\mathrm{CO} 2}$ value required for phrenic inspiratory bursting was determined as previously described (Sandhu et al., 2010). $\mathrm{PET}_{\mathrm{CO} 2}$ was then monitored continuously, and maintained at $2 \mathrm{mmHg}$ above the onset threshold value by changing the ventilator rate as needed. After a 10-min baseline period, an arterial blood sample was drawn. Rats were then exposed to a 5-min period of hypoxia $\left(\mathrm{FIO}_{2}=0.12-\right.$ 0.14), and a blood sample was obtained during the final minute to verify the arterial hypoxemia. After 10-min, rats were exposed to a 5-min bout of hypercapnia (PET $\mathrm{CO}_{\mathrm{CO}} \sim 80 \mathrm{mmHg}$ ) achieved by raising the inspired $\mathrm{CO}_{2}$ concentration. Ten-min after the hypercapnic exposure, a final "maximal" respiratory challenge was induced by ceasing the mechanical ventilation for a brief period (10-20 s). This procedure produces a maximum respiratory output in this preparation 
(Golder et al., 2003). Analysis of phrenic neurograms was done using Spike 2 software. The integrated phrenic neurogram was used to calculate $\int \mathrm{Phr}$ burst amplitude $(\mathrm{mV})$ and frequency (bursts/min). Data were averaged over 1-min intervals during baseline immediately prior to the first respiratory challenge, and at the end of the hypoxic and hypercapnic exposures. During the final maximal chemoreceptor challenge, the peak 3 inspiratory bursts were averaged.

\section{Immunohistochemistry and Stereology}

The presence of GFP-positive cells at or near the site of spinal cord injection was confirmed in all NPC transplant rats in which phrenic nerve recordings and plethysmography data were obtained (e.g., cohorts 1 and 2). GFP-positive cells were identified using either native fluorescence or antibodies against GFP. The latter procedure was done in a subset of rats to enable quantitative stereology as described subsequently.

At the conclusion of neurophysiology data collection, an adequate plane of anesthesia was confirmed by absence of a heart rate or arterial blood pressure response to compressive toe pinch and rats were euthanized by systemic perfusion (via the aorta) with heparinized saline followed by paraformaldehyde ( $4 \% \mathrm{w} / \mathrm{v}$ in $0.1 \mathrm{M}$ PBS, $\mathrm{pH}=7.4)$. The animals in the third cohort were euthanized via a lethal dose of Beuthanasia (9:1, sodium pentobarbitone to phenytoin solution) and then systemically perfused with heparinized saline followed by $4 \%$ paraformaldehyde. The cervical spinal cords were removed and stored in PBS for $24 \mathrm{hrs}$ at $4^{\circ} \mathrm{C}$. Tissues were then sectioned on a vibratome (40 $\mu \mathrm{m}$ thickness) and transferred in fresh PBS within a 96-well plate. For immunostaining, sections were blocked with $10 \%(\mathrm{v} / \mathrm{v})$ normal goat serum in $0.1 \mathrm{M}$ PBS for $60 \mathrm{~min}$ and then incubated with primary antibody overnight at $4^{\circ} \mathrm{C}$.

The following primary antibodies were used: chicken anti-green fluorescent protein (antiGFP, 1:1000; Aves Labs, OR) for transplanted NPCs, mouse anti-GFAP (1:100; Abcam, Cambridge, MA) for astrocytes and mouse anti-vimentin (1:500; EnCor Biotechnology, Gainesville, FL) for immature astrocytes, rabbit anti- $\beta$ tubulin III (1:500 to 1:1000; Abcam, 
Cambridge, MA) for immature neurons, as well as mouse anti-oligodendrocyte marker $\mathrm{O} 4$ (1:100 to 1:500; Sigma-Aldrich, St. Louis, MO), rabbit anti-CNPase (1:200 to 1:500; Abcam, Cambridge, MA), mouse anti-MBP (1:1000; EMD Millipore, Billerica, MA) and mouse antioligodendrocyte marker O1 (1:500 to 1:1000; Sigma Aldrich, St. Louis, MO) for oligodendrocytes. For the secondary labeling, tissue was incubated with goat anti-chicken secondary antibody conjugated to Alexa Fluor 488 or Alexa Flour 594 (1:500, Life Technologies, Grand Island, NY) for 2 hr. Tissue sections were washed three times with PBS, slide mounted and cover-slipped with mounting medium containing DAPI nuclear counterstain. Immunofluorescent images were taken using an Olympus 1X81-DSN spinning disk confocal microscope equipped with a Hamamatsu CCD digital camera. Image analysis was done using Slidebook software (Intelligent Imaging innovations, CO) and post-analysis was done in Photoshop software (Adobe Systems, CA).

For brightfield microscopy, spinal cord sections were incubated overnight in chicken antigreen fluorescent protein (anti-GFP, 1:40,000; Aves Labs, OR). The following day, sections were incubated in goat anti-chicken DSB-X biotin secondary antibody (1: 200, Invitrogen, CA) for $2 \mathrm{hr}$, followed by incubation in $A B C$ reagent (Vectastain $A B C$ kit, Vector laboratories, Burlingame, CA, USA) for $2 \mathrm{hr}$ and then developed in freshly prepared diaminobenzidine peroxidase substrate solution to detect EGFP (conjugated with biotin, brown). Tissues were also counter-stained with cresyl violet for morphology and then examined with light microscopy. In a subset of animals $(\mathrm{N}=8)$, the number of $\mathrm{DAB}$-positive transplanted cells in the cervical spinal cord was quantified with unbiased stereology using a Zeiss Axiolmager A1 light microscope under a 10x objective lens for tracing and a 40x objective lens for counting and Microbrighfield Stereolnvestigator software (Banuelos et al., 2013). NPC yield was quantified by counting EGFP-positive nuclei in every $4^{\text {th }}$ section using the Optical Fractionator probe, and Serial Section Manager. Three separate regions were counted: the gray matter, the dorsal columns 
and the ventrolateral white matter. Cavalieri's Principle was applied to extrapolate the area and volume of the cell graft (Gundersen et al., 1988).

\section{Statistical Analyses}

Statistical tests were done using SigmaPlot v.12 software. A two-way repeated measures analyses of variance (ANOVA) followed by the Student-Neuman-Keuls post hoc test was used to assess plethysmography data: factor $1=$ time $(4-$ or 8 -wk), factor $2=$ treatment group (transplant or control). The same statistical test was used to compare phrenic nerve activity between groups: factor $1=$ treatment (NPC transplant or control), factor $2=$ condition (baseline, hypoxia, hypercapnia or maximal challenge). If the data were not normally distributed, a log transformation procedure was done before proceeding with the ANOVA. Differences were considered statistically significant when the $P$ value $\leq 0.05$. Microbrightfield Stereolnvestigator software was used to extrapolate graft volume from the cell counts derived from the stereology analyses. A one-way ANOVA with Student-Neuman-Keuls post hoc test was used to compare the number of transplanted cells in the gray matter, dorsal white matter and ventral white matter. All data are presented as the mean \pm 1 standard deviation.

\section{Results}

In vitro characterization of neural precursor cells

Prior to transplantation experiments, the in vitro fate of SVZ-derived neurosphere populations was examined following culture in the absence of proliferative growth factors (Ross et al., 2008). The results confirmed that the harvested NPC population was capable of in vitro differentiation into a heterogeneous population that included neuronal and astrocytic phenotypes (Fig. 1). A primarily bipolar morphology was observed in cells that stained positively for B-III tubulin, indicative of a neuroblast phenotype. Other cells that stained positively for GFAP exhibited a flattened, multipolar morphology consistent with a neurosphere- 
derived astrocytic phenotype as previously described (Ross et al., 2011; Ross et al., 2012). On average, approximately one third of cells (32 $\pm 13 \%)$ were immunopositive for $B$-III tubulin and $10 \pm 5 \%$ were positive for GFAP (Fig. 1). Positive staining for mature oligodendrocyte markers was not observed, and this result is consistent with prior reports conducted at this early stage of mitogen withdrawal (Ross et al., 2011; Ross et al., 2012). Also consistent with a prior report, a small percentage of the cells retained progenitor-like qualities (Ross et al., 2012) .

\section{C2Hx histology and body weight}

Post-mortem histological evaluation of the cervical spinal cord showed that $93 \%$ of rats had anatomically complete hemi-lesions which extended to the spinal midline. Two animals had clearly discernable sparing of white matter in the C2 spinal cord ipsilateral to the lesion, and were thus considered to have incomplete lesions (Fuller et al., 2009). These rats were excluded from the study per our a priori exclusion criteria. Across the two time points (i.e., 4- vs. 8-wks post-transplant), body weight was not significantly different between groups $\left(F_{1,24}=1.370\right.$, $P=0.253)$, and a significant effect of time was observed $\left(F_{1,24}=4.855, P=0.038\right)$. The NPC group tended to be heavier at 4 -wks $(270 \pm 11 \mathrm{~g})$ compared to control $(260 \pm 17 \mathrm{~g} ; \mathrm{P}=0.110)$, but body weight was indistinguishable after 8-wks (NPC: $271 \pm 10 \mathrm{~g}$; Control: $269 \pm 22 \mathrm{~g}$; P=0.747).

\section{Distribution and differentiation of the transplanted NPCs}

At 8-weeks post-transplantation, SVZ-derived NPCs could be readily visualized in the spinal cord by light microscopy following GFP immunochemistry procedures (Fig. 2A-F). These cells were most prominent in the immediate vicinity of the injection site, and were found primarily in the white matter ipsilateral to the $\mathrm{C} 2 \mathrm{Hx}$ lesion. GFP-positive cells were observed much less frequently in the contralateral spinal cord (e.g., Fig. 2A). The density of GFP-positive cells rapidly decreased with distance from the injection site, but cells could be observed up to 3 $\mathrm{mm}$ distant from the injection in the rostral or caudal direction (Fig. 2B-C). 
Stereological quantification revealed an average of 321,488 $\pm 85,233$ GFP-labeled cells per animal, which indicates a $48 \%$ survival rate of the transplanted cells. Quantitative extrapolation using Stereolnvestigator software indicated that the overall surface area of the transplanted cells was $62 \pm 14 \mathrm{~mm}^{2}$ with a density of $4,951 \pm 607$ cells per $\mathrm{mm}^{2}$. Most of the GFPpositive cells $(70 \pm 3 \%)$ were found in ventral spinal white matter. The remaining cells were observed in dorsal white matter $(19 \pm 4 \%)$ and throughout the gray matter $(11 \pm 2 \%)$. The morphologic appearance of the GFP positive transplant cells in the injured spinal cord can be appreciated from panels E and F of Fig. 2. There were no indications of abhorrent growth (e.g., tumorigenesis) either on gross exam of the spinal cord or during microscopy evaluation of spinal histology.

Immunohistochemistry confirmed that at least a subset of the transplanted cells developed along an astrocyctic lineage. Quantitative analyses using confocal microscopy revealed that $20 \pm 4 \%$ of the transplanted cells were co-labeled with GFAP (e.g., Fig. 2G-J), and $17 \pm 3 \%$ were immunoreactive for vimentin (Fig. $2 \mathrm{l}-\mathrm{L}$ ), both of which are consistent with an astrocytic phenotype. No $\beta$-III tubulin immunoreactivity could be detected in GFP-positive cells. Thus, consistent with prior reports (Cao et al., 2001; Pfeifer et al., 2004; Vroemen et al., 2003), there was no evidence for a neuronal phenotype in the transplanted NPCs. Similarly, multiple oligodendrocyte-related antibodies were tested including CNPase, NG2, PDGFR, Olig2, and no positive staining could be detected in transplanted cells.

\section{Respiratory outcomes after cervical NPC transplantation}

Phrenic neuromotor output was directly assessed via extracellular nerve recordings under standardized conditions in anesthetized rats at 8-wks post-transplantation (e.g., Fig. 3A). These experiments indicated that the inspiratory output of the phrenic nucleus ipsilateral to the $\mathrm{C} 2 \mathrm{Hx}$ lesion was increased following NPC transplant. Robust increases in ipsilateral phrenic motor output were detected across a range of experimental conditions associated with low to 
very high "respiratory motor drive" in the NPC transplant group (Fig. 3). The physiological conditions in which phrenic output was evaluated, however, were similar between groups as shown by the MAP, $\mathrm{PaO}_{2}, \mathrm{PaCO}_{2}$ and arterial $\mathrm{pH}$ values in Table 1.

As discussed in depth previously (Fuller et al., 2009; Nichols and Mitchell, 2015) the absolute value of extracellularly recorded phrenic nerve activity can provide a valuable index of neuromotor output, particularly after neurologic injury. Note that Figs. 3B-E, which depict phrenic output across both experimental groups, display each individual data point as well as the overall group mean. Fig. 3B demonstrates the significant increase in ipsilateral phrenic bursting $(\mathrm{v})$ after NPC compared to control $\left(\mathrm{F}_{1,21}=14.753, \mathrm{P}<0.001\right)$. There was also an impact of condition (e.g., baseline through maximal challenge; $\mathrm{F}_{3,63}=79.753, \mathrm{P}<0.001$ ) that is most apparent in the NPC group. When the ipsilateral phrenic burst amplitude was expressed relative to the simultaneously recorded contralateral phrenic burst (Fig. 3C), a robust impact of NPC transplantation was also detected $\left(F_{3,63}=6.438, P=0.019\right)$ as were differences across condition $\left(\mathrm{F}_{3,63}=22.922, \mathrm{P}<0.001\right)$. Differences in contralateral phrenic bursting were not detected across groups regardless of the approach to data quantification. Fig. 3D depicts the absolute output of the contralateral phrenic nerve across all conditions; there was no observable treatment effect $\left(F_{1,21}=0.598, P=0.448\right)$. Similarly, no differences in the inspiratory phrenic burst frequency (burst per minute) were detected across the two experimental groups (Fig. 3E, $\left.F_{1,21}=0.059, P=0.810\right)$. Note that most rats showed an initial increase in burst frequency during hypoxia and hypercapnia (e.g., Fig. 3A), but this was followed by a "roll-off" in burst frequency towards baseline values.

The nerve recording data provided an opportunity to probe for a relationship between the appearance of the NPC graft and phrenic neuromotor output in a given animal. Of the $\mathrm{N}=8$ rats in which stereological quantification was done, successful phrenic nerve recording protocols were accomplished in $\mathrm{N}=4$. Although the sample size for this specific analyses (i.e. $\mathrm{N}=4$ with both stereology and phrenic recordings) is modest, a striking and highly significant relationship 
was observed between the peak phrenic burst amplitude and the stereologically quantified number of GFP-positive cells ( $P<0.001$, Spearman's rank correlation). Thus, the total number of GFP-positive cells in the cervical spinal cord was predictive of the peak phrenic burst amplitude.

The rate and depth of breathing in unanesthetized rats was examined using whole-body plethysmography at 4- and 8-wks post-transplant (e.g., Fig. 4A). During baseline conditions at both the 4- and 8-wk time points, the breathing patterns (e.g., inspiratory tidal volume, frequency, airflow rates, etc.) were similar between the transplant and control groups (all data are reported in Table 2). Thus, both groups adopted the rapid, shallow breathing pattern that has been repeatedly described in rats with $\mathrm{C} 2 \mathrm{Hx}$ injury (Fuller et al., 2008; Fuller et al., 2006), and the NPC transplant had no detectable impact on "eupneic" normoxic breathing.

During conditions associated with increased respiratory motor drive, highly statistically significant differences in the pattern of breathing were detected between the two groups. During an hypoxic challenge ( $10 \%$ inspired $\mathrm{O}_{2}$ ), inspiratory tidal volume (mls per breath) was greater in NPC vs. control rats $\left(F_{1,24}=11.007, P=0.003\right)$. As shown in Fig. $4 B$, this effect was present at both 4- and 8-wks. A similar conclusion was reached when tidal volume was expressed per $100 \mathrm{~g}$ body mass (Fig. 4C, $\mathrm{F}_{1,24}=6.392, \mathrm{P}=0.0 .018$ ). For hypoxic breathing frequency, there was a significant interaction between time and treatment $\left(F_{1,22}=8.841, P=0.007\right)$. Thus, as shown in Fig. 4D, the NPC group took fewer breaths per minute during the hypoxic challenge at 8- but not 4-wks post-injury. At both 4- and 8-wks, the overall level of minute ventilation (expressed as either $\mathrm{mls} / \mathrm{min}$ or $\mathrm{mls} / \mathrm{min} / 100 \mathrm{~g}$ body mass) was similar between the NPC and control groups during hypoxia (Table 3), but as already indicated, the NPC group adopted a larger volume, lower frequency pattern compared to control.

Rats were also exposed to a hypercapnic respiratory challenge $\left(7 \%\right.$ inspired $\left.\mathrm{CO}_{2}\right)$ during the whole body plethysmography experiments. Qualitatively similar results to the hypoxia challenge were obtained in regards to inspiratory volume. Thus, NPC rats had significantly 
larger inspiratory volumes (mls per breath) during hypercapnia (Fig. 4E; $F_{1,24}=6.303, P=0.019$ ). When normalized to body weight (mls per breath per 100g), the NPC transplant group showed a strong tendency for increased volume (Fig. 4F, $F_{1,24}=3.683, P=0.068$ ). As with the hypoxia challenge, hypercapnic breathing frequency and overall minute ventilation were similar between NPC and control groups (Table 4).

\section{Discussion}

This investigation shows that intraspinal transplantation of SVZ-derived NPCs, delivered immediately caudal to high cervical $\mathrm{SCl}$, results in improved respiratory motor recovery. Greater inspiratory phrenic output was observed ipsilateral to the $\mathrm{C} 2 \mathrm{Hx}$ lesion (i.e., enhanced "crossed phrenic" activity) at 8-wks following NPC transplant, and this occurred in parallel with greater inspiratory tidal volume during periods of increased respiratory neuromotor drive. The transplanted NPCs were histologically verified to migrate primarily within white matter (KarimiAbdolrezaee et al., 2006b), and were almost exclusively distributed ipsilateral to the lesion. Consistent with earlier reports (Cao et al., 2001; Karimi-Abdolrezaee et al., 2006b), we observed no evidence for neuronal differentiation upon transplantation of the precursor cells. Accordingly, the observed increases in phrenic motor output and inspiratory tidal volume most likely reflect modulation of existing spinal synaptic pathways to phrenic motoneurons.

\section{Respiratory recovery after $\mathrm{C} 2 \mathrm{Hx}$ and the impact of NPC transplantation}

Bulbospinal projections to the ipsilateral phrenic motor pool are axotomized by $\mathrm{C} 2 \mathrm{Hx}$ and this immediately paralyzes the ipsilateral hemidiaphragm. After $\mathrm{C} 2 \mathrm{Hx}$, however, there is a timedependent spontaneous recovery of ipsilateral phrenic motor output over a period of weeksmonths (Nantwi, 1999; Pitts, 1940). This spontaneous recovery is not complete, and deficits in both ipsilateral diaphragm (phrenic) output and inspiratory tidal volume persist following the injury (Dougherty et al., 2012; Fuller et al., 2008). The spontaneous recovery of ipsilateral 
phrenic motor activity is serotonin dependent (Golder et al., 2001), and reflects activation of latent synaptic pathways to phrenic motoneurons which project across the spinal midline caudal to the lesion (Goshgarian, 2003). The recovery also may involve formation of de novo polysynaptic spinal cord circuits (Lane et al., 2009; Lane et al., 2008). The spontaneous phrenic motor recovery process can be augmented by a variety of experimental manipulations including administration of theophylline (Nantwi et al., 1996; Nantwi and Goshgarian, 1998) or serotonin receptor agonists (Zhou et al., 2001; Zhou and Goshgarian, 2000), spinal delivery of brain derived neurotrophic factor (Mantilla et al., 2013; Martinez-Galvez et al., 2016), and also exposure to intermittent hypoxia paradigms (Fuller et al., 2003; Navarrete-Opazo et al., 2015). Thus, as originally noted by Guth, the spinal "crossed phrenic pathways" which underlie the ipsilateral phrenic recovery are capable of considerable plasticity (Guth, 1976). Here we found that delayed (1-wk post $\mathrm{C} 2 \mathrm{Hx}$ ) transplantation of SVZ-derived NPCs induced plasticity in crossed phrenic pathways as evidenced by enhanced ipsilateral phrenic motor output recorded 8-wks later.

Crossed phrenic activation of the ipsilateral hemidiaphragm makes a small but functionally significant biomechanical contribution to breathing (Dougherty et al., 2012; Golder et al., 2003). Accordingly, the increase in ipsilateral phrenic motor output after NPC transplant (assessed in anesthetized rats) likely contributed to the increased inspiratory tidal volume recorded in unanesthetized rats (Fig. 4). Increased tidal volume, however, was only detected under conditions of elevated respiratory drive. Therefore, in the awake rat, the functional benefits of the NPC transplant were manifest only during periods of respiratory challenge when synaptic inputs to respiratory motoneurons are elevated above quiet breathing or "eupneic" conditions. This observation may reflect the fact that the $\mathrm{C} 2 \mathrm{Hx}$ lesion does not cause hypoventilation during quiet breathing, and reductions in minute ventilation are only detected during respiratory stimulation (Fuller et al., 2008; Fuller et al., 2006; Fuller et al., 2009). 
Potential mechanisms of recovery.

Determination of the specific cellular and/or synaptic mechanisms by which the intraspinal NPC transplantation modulated respiratory recovery was beyond the scope of our study, but the histologic outcomes nevertheless provide some insight into this question. First, the transplanted NPCs migrated almost exclusively to the spinal cord ipsilateral to the lesion, and were distributed primarily within white matter. The cells were not exclusively restricted to the immediate location of the injury, but migrated small distances both rostrally and caudally. Exogenously delivered NPCs can migrate within the CNS using navigational cues provided by local inflammatory responses (Carbajal et al., 2010), and thus local inflammation may have contributed to the distribution of cells observed in the current study. The most salient point is that the focal distribution of the transplanted cells suggests that their functional impact reflected mechanisms which were localized within the immediate vicinity of the $\mathrm{C} 2 \mathrm{Hx}$ lesion and/or the rostral portion of the ipsilateral phrenic motor nucleus. This suggestion is supported by the recordings from the phrenic nerve contralateral to $\mathrm{C} 2 \mathrm{Hx}$. In sharp contrast to increased ipsilateral phrenic output, contralateral phrenic nerve activity was not altered following the NPC transplant. If the transplant had altered bulbospinal respiratory inputs to the spinal cord (e.g., due to a change in central chemosensitivity), the impact would likely have been detected bilaterally in the phrenic nerve recordings. Another consideration is that the phrenic nerve recordings were made under carefully controlled conditions which included a constant rate of ventilation, elimination of vagal afferent feedback, and stable arterial blood gases. Under these conditions, inspiratory frequency (i.e., bursts per minute) was similar between the NPC transplant vs. control group, and this further suggests that brainstem control of breathing mechanisms were not altered by the transplant.

Neuronal replacement strategies have been studied in the $\mathrm{C} 2 \mathrm{Hx}$ model, with some evidence for improved respiratory function (Dougherty et al., 2016; White et al., 2010). In the current experiments, however, we observed no evidence that neurons were derived from the 
SVZ-derived NPC transplants, and this is consistent with prior reports (Cao et al., 2001; KarimiAbdolrezaee et al., 2006b). Accordingly, neuronal replacement can likely be ruled out as part of the mechanisms contributing to the observed respiratory recovery. We observed that a portion of the transplanted cells (verified by GFP staining) were positive for GFAP, and additional GFPpositive cells were positive for vimentin, a marker of both mature and immature astrocytes (Yang et al., 1993). The GFAP staining is consistent with a previous study in which SVZderived NPCs were delivered to the cervical dorsal columns in the adult rat (Mligiliche et al., 2005). Based on these histological data, we suggest that the enhanced phrenic motor output and ventilation after NPC transplant was either directly or indirectly related to astrocytes derived from the donor cells. This suggestion also derives from previous work that very clearly establishes that transplantation of astrocytes can improve outcomes after SCl (Davies et al., 2006; Haas and Fischer, 2013; Hayakawa et al., 2016; Jin et al., 2016; Mligiliche et al., 2005). Davies et al. (2006) showed that intraspinal transplantation of astrocytes improved locomotor function after transection of the C3-4 dorsolateral funiculus in adult rats. In addition, a similar transplant procedure was associated with increased axonal growth after C1-2 dorsal column lesion (Davies et al., 2006). Intraspinal transplantation of astrocytes derived from glial-restricted progenitors (GRPs) can promote regeneration of sensory axons after C4-5 dorsal column lesion in rats (Haas and Fischer, 2013), and recent efforts from the Fisher laboratory have shown that directional cues provided by viral mediated expression of growth factors can produce a "migratory stream" of GRPs to better direct axonal growth (Yuan et al., 2016). LePore and colleagues have published a series of studies exploring the impact of astrocyte transplantation on respiratory-related outcomes cervical SCI in rodents (Li et al., 2015a; Li et al., 2015b). They have conclusively demonstrated that following C4 contusion injury, transplantation of astrocytes genetically modified to express high levels of glutamate transport proteins will reduce lesion size, motor neuron loss, and enhance respiratory recovery ( $\mathrm{Li}$ et al., 2015a). It is unclear if a similar "neuroprotection" mechanism could have occurred in the current study, particularly since 
$\mathrm{C} 2 \mathrm{Hx}$ is primarily a white matter lesion. However, a recent report suggests that this may be a possibility (Satkunendrarajah et al., 2016).

\section{Summary}

The current results confirm the feasibility of transplanting SVZ-derived NPCs in the injured cervical spinal cord (Mligiliche et al., 2005), and show that transplant was associated with enhanced phrenic motor output and inspiratory tidal volume. The results also provide further evidence that transplantation of astrocytes can be beneficial following SCI (Davies et al., 2006; Haas and Fischer, 2013; Li et al., 2015a). Future work should focus on confirming the post-transplantation developmental fate of the entire NPC population, and determining the specific physiological mechanisms by which the transplant procedure modulated respiratory recovery.

Acknowledgements. We are grateful for the histological and immunochemistry assistance of Marda Jorgenson and Rachel Mattio. Funding was provided by NIH 1R01NS080180-01A1 (DDF), NIH 1 R01 NS054025-06 (PJR), NIH R03 AG049411 (BKO), the State of Florida Brain and Spinal Cord Injury Research Trust Fund (DDF and PJR), the DoD PR12179 (BKO) and a Postdoctoral Fellowship from the Craig H. Neilsen Foundation (220521, MSS). 


\section{Figure Legends}

Fig. 1. In vitro characterization of neural precursor cells. Prior to transplantation experiments, the in vitro fate of SVZ-derived neurosphere populations was examined. On average, approximately one third of cells were immunopositive for $B$-III tubulin and $10 \%$ were positive for GFAP (panel A). A bipolar morphology was observed in cells which stained positively for B-III tubulin (panel B), indicative of a neuroblast phenotype. Cells staining for GFAP (panel C) possessed a flattened, multipolar morphology.

\section{Fig. 2. Migration and differentiation of SVZ-derived NPCs after transplantation into the} injured cervical spinal cord. Panel A shows a C3 transverse histological section at the approximate site of the NPC injection (i.e., immediately caudal to the C2 injury) obtained 8-wks following the transplantation procedure. Panel B shows a section from the $\mathrm{C} 1 / \mathrm{C} 2$ border which illustrates the rostral migration of transplanted cells. A histological example obtained at the site of the $\mathrm{C} 2 \mathrm{Hx}$ injury is shown in Panel $\mathrm{C}$. Panels $\mathrm{D}$ and $\mathrm{E}$ show higher magnification views of the areas highlighted by the boxes in Panel $A$. The image shown in panel $F$ is a magnified view of the region indicated by the arrow in Panel C. Panels G-N show histological examples which demonstrate co-labeling of the transplanted cells with GFAP (marker for astrocytes) and vimentin (a cytoskeletal intermediate filament protein). In the sequence of images shown in GI, the same section of cervical white matter is shown to illustrate co-localization of the transplanted SVZ-derived neurons (which are GFP-positive and therefore green) with GFAP (red) and DAPI (blue). The same area of tissue is shown as a three dimensional rendering in Panel J. These images confirm that a subset of the transplanted NPCs developed along an astrocytic lineage. Panels K-M demonstrate co-localization of transplanted GFP-positive cells with vimentin (red) and DAPI (blue), and a three dimensional rendering is provided in N. These images are representative of the data used to determine that subsets of the transplanted 
neurons were co-labeled with vimentin, which is also consistent with an astrocytic phenotype. Scale bars: $500 \mu \mathrm{m}$ in panels $A-C, 200 \mu \mathrm{m}$ in panel $\mathrm{D}, 50 \mu \mathrm{m}$ in panels $\mathrm{E}-\mathrm{F}$, and $20 \mu \mathrm{m}$ in panels $\mathrm{G}, \mathrm{H}, \mathrm{I}, \mathrm{K}, \mathrm{L}$ and $\mathrm{M}$.

Figure 3. The impact of SVZ-derived NPC transplantation on phrenic motor output in anesthetized rats. In panel A, representative records of phrenic nerve activity recorded ipsilateral to $\mathrm{C} 2 \mathrm{HX}$ are shown. The record is compressed such that approximately 30 -min of data can be viewed. The amplitude of the integrated phrenic inspiratory burst is shown (top panel) during the baseline period followed by the three successive respiratory challenges: hypoxia, hypercapnia (H-Cap), and combined hypoxia-hypercapnia (Max). The instantaneous inspiratory phrenic burst frequency and the arterial blood pressure are shown below the phrenic nerve trace. These example records illustrate the primary finding that greater inspiratory phrenic burst amplitudes were observed in the ipsilateral nerve in rats that had received the transplant. Mean phrenic data are presented in panels B-E. Note that each individual data point is shown along with the group mean and standard deviation. Both the raw output of the ipsilateral nerve (B) and the normalized output (\% of contralateral burst, C) were statistically greater over a wide range of conditions in the transplant group as compared to the control. No differences in contralateral bursting were detected (D), and inspiratory burst frequency was also similar between the groups $(\mathrm{E})$. Data were analyzed using two-way repeated measures ANOVA, and the P-values derived from post hoc comparisons are shown when significant differences were detected (i.e., panels B and C).

Figure 4. The impact of SVZ-derived NPC transplantation on the pattern of breathing during respiratory challenge in unanesthetized rats. Panel A illustrates example recordings obtained using whole body plethysmography in unrestrained rats at the eight-week time point. These example records illustrate the primary finding that baseline pattern of breathing was 
similar between the groups (see Table 2), but during the challenge condition (the example shown is during hypoxia) rats with the NPC transplant typically produced larger inspiratory volumes. Panels B-D show the responses from each individual experiment as well as the mean and standard deviation during the hypoxic challenge at both four and eight weeks post injury. The data presented include the inspiratory tidal volume in mls (B), mls per 100 gram body weight $(C)$ and breathing frequency (breaths per min, D). Note there is some variability in the data, but that average inspiratory tidal volume is significantly enhanced in the group receiving the NPC transplant, and that breathing frequency is reduced at the eight-week time point. Panels E-G are formatted similarly, and show the pattern of breathing that occurred during hypercapnic respiratory challenge. The same tendencies that occurred during hypoxic challenge were noted, but in most cases did not achieve statistical significance. 


\section{References}

Alvarez-Buylla, A., Seri, B., Doetsch, F., 2002. Identification of neural stem cells in the adult vertebrate brain. Brain Res Bull 57, 751-758.

Baker-Herman, T.L., Bavis, R.W., Dahlberg, J.M., Mitchell, A.Z., Wilkerson, J.E., Golder, F.J., Macfarlane, P.M., Watters, J.J., Behan, M., Mitchell, G.S., 2009. Differential expression of respiratory long-term facilitation among inbred rat strains. Respir Physiol Neurobiol.

Banuelos, C., LaSarge, C.L., McQuail, J.A., Hartman, J.J., Gilbert, R.J., Ormerod, B.K., Bizon, J.L., 2013. Age-related changes in rostral basal forebrain cholinergic and GABAergic projection neurons: relationship with spatial impairment. Neurobiology of aging 34, 845-862.

Bonner, J.F., Connors, T.M., Silverman, W.F., Kowalski, D.P., Lemay, M.A., Fischer, I., 2011. Grafted neural progenitors integrate and restore synaptic connectivity across the injured spinal cord. J Neurosci 31, 4675-4686.

Cao, Q.L., Zhang, Y.P., Howard, R.M., Walters, W.M., Tsoulfas, P., Whittemore, S.R., 2001. Pluripotent stem cells engrafted into the normal or lesioned adult rat spinal cord are restricted to a glial lineage. Experimental neurology 167, 48-58.

Carbajal, K.S., Schaumburg, C., Strieter, R., Kane, J., Lane, T.E., 2010. Migration of engrafted neural stem cells is mediated by CXCL12 signaling through CXCR4 in a viral model of multiple sclerosis. Proc Natl Acad Sci U S A 107, 11068-11073.

Davies, J.E., Huang, C., Proschel, C., Noble, M., Mayer-Proschel, M., Davies, S.J., 2006. Astrocytes derived from glial-restricted precursors promote spinal cord repair. Journal of biology 5,7 .

Doperalski, N.J., Fuller, D.D., 2006. Long-term facilitation of ipsilateral but not contralateral phrenic output after cervical spinal cord hemisection. Experimental neurology 200, 74-81.

Dougherty, B.J., Gonzalez-Rothi, E.J., Lee, K.Z., Ross, H.H., Reier, P.J., Fuller, D.D., 2016. Respiratory outcomes after mid-cervical transplantation of embryonic medullary cells in rats with cervical spinal cord injury. Experimental neurology 278, 22-26.

Dougherty, B.J., Lee, K.Z., Lane, M.A., Reier, P.J., Fuller, D.D., 2012. Contribution of the spontaneous crossed-phrenic phenomenon to inspiratory tidal volume in spontaneously breathing rats. J Appl Physiol 112, 96-105.

Fischer, I., 2000. Candidate cells for transplantation into the injured CNS. Prog Brain Res 128, 253-257.

Fuller, D.D., Doperalski, N.J., Dougherty, B.J., Sandhu, M.S., Bolser, D.C., Reier, P.J., 2008. Modest spontaneous recovery of ventilation following chronic high cervical hemisection in rats. Experimental neurology 211, 97-106.

Fuller, D.D., Golder, F.J., Olson, E.B., Jr., Mitchell, G.S., 2006. Recovery of phrenic activity and ventilation after cervical spinal hemisection in rats. J Appl Physiol 100, 800-806.

Fuller, D.D., Johnson, S.M., Olson, E.B., Jr., Mitchell, G.S., 2003. Synaptic pathways to phrenic motoneurons are enhanced by chronic intermittent hypoxia after cervical spinal cord injury. The Journal of neuroscience : the official journal of the Society for Neuroscience 23, 2993-3000.

Fuller, D.D., Sandhu, M.S., Doperalski, N.J., Lane, M.A., White, T.E., Bishop, M.D., Reier, P.J., 2009. Graded unilateral cervical spinal cord injury and respiratory motor recovery. Respiratory physiology \& neurobiology 165, 245-253.

Golder, F.J., Fuller, D.D., Davenport, P.W., Johnson, R.D., Reier, P.J., Bolser, D.C., 2003. Respiratory motor recovery after unilateral spinal cord injury: eliminating crossed phrenic activity decreases tidal volume and increases contralateral respiratory motor output. The Journal of neuroscience : the official journal of the Society for Neuroscience 23, 2494-2501.

Golder, F.J., Reier, P.J., Bolser, D.C., 2001. Altered respiratory motor drive after spinal cord injury: supraspinal and bilateral effects of a unilateral lesion. The Journal of neuroscience : the official journal of the Society for Neuroscience 21, 8680-8689. 
Goshgarian, H.G., 2003. The crossed phrenic phenomenon: a model for plasticity in the respiratory pathways following spinal cord injury. J Appl Physiol 94, 795-810.

Gundersen, H.J., Bagger, P., Bendtsen, T.F., Evans, S.M., Korbo, L., Marcussen, N., Moller, A., Nielsen, K., Nyengaard, J.R., Pakkenberg, B., et al., 1988. The new stereological tools: disector, fractionator, nucleator and point sampled intercepts and their use in pathological research and diagnosis. APMIS : acta pathologica, microbiologica, et immunologica Scandinavica 96, 857-881.

Guth, L., 1976. Functional plasticity in the respiratory pathway of the mammalian spinal cord. Experimental neurology 51, 414-420.

Haas, C., Fischer, I., 2013. Human astrocytes derived from glial restricted progenitors support regeneration of the injured spinal cord. Journal of neurotrauma 30, 1035-1052.

Hayakawa, K., Haas, C., Fischer, I., 2016. Examining the properties and therapeutic potential of glial restricted precursors in spinal cord injury. Neural regeneration research 11, 529-533.

Jin, Y., Bouyer, J., Shumsky, J.S., Haas, C., Fischer, I., 2016. Transplantation of neural progenitor cells in chronic spinal cord injury. Neuroscience 320, 69-82.

Karimi-Abdolrezaee, S., Eftekharpour, E., Wang, J., Morshead, C., Fehlings, M., 2006a. Transplants of adult neural precursors in combination with growth factors and minocycline promote successful remyelination and neurobehavioral recovery after spinal cord injury. Journal of Neurotrauma 23, 785785.

Karimi-Abdolrezaee, S., Eftekharpour, E., Wang, J., Morshead, C.M., Fehlings, M.G., 2006b. Delayed transplantation of adult neural precursor cells promotes remyelination and functional neurological recovery after spinal cord injury. The Journal of neuroscience : the official journal of the Society for Neuroscience 26, 3377-3389.

Lane, M.A., Lee, K.Z., Fuller, D.D., Reier, P.J., 2009. Spinal circuitry and respiratory recovery following spinal cord injury. Respiratory physiology \& neurobiology 169, 123-132.

Lane, M.A., White, T.E., Coutts, M.A., Jones, A.L., Sandhu, M.S., Bloom, D.C., Bolser, D.C., Yates, B.J., Fuller, D.D., Reier, P.J., 2008. Cervical prephrenic interneurons in the normal and lesioned spinal cord of the adult rat. The Journal of comparative neurology 511, 692-709.

Li, K., Javed, E., Hala, T.J., Sannie, D., Regan, K.A., Maragakis, N.J., Wright, M.C., Poulsen, D.J., Lepore, A.C., 2015a. Transplantation of glial progenitors that overexpress glutamate transporter GLT1 preserves diaphragm function following cervical SCI. Molecular therapy : the journal of the American Society of Gene Therapy 23, 533-548.

Li, K., Javed, E., Scura, D., Hala, T.J., Seetharam, S., Falnikar, A., Richard, J.P., Chorath, A., Maragakis, N.J., Wright, M.C., Lepore, A.C., 2015b. Human iPS cell-derived astrocyte transplants preserve respiratory function after spinal cord injury. Experimental neurology 271, 479-492.

Llado, J., Haenggeli, C., Maragakis, N.J., Snyder, E.Y., Rothstein, J.D., 2004. Neural stem cells protect against glutamate-induced excitotoxicity and promote survival of injured motor neurons through the secretion of neurotrophic factors. Molecular and cellular neurosciences 27, 322-331.

Mantilla, C.B., Gransee, H.M., Zhan, W.Z., Sieck, G.C., 2013. Motoneuron BDNF/TrkB signaling enhances functional recovery after cervical spinal cord injury. Experimental neurology 247, 101-109.

Martinez-Galvez, G., Zambrano, J.M., Diaz Soto, J.C., Zhan, W.Z., Gransee, H.M., Sieck, G.C., Mantilla, C.B., 2016. TrkB gene therapy by adeno-associated virus enhances recovery after cervical spinal cord injury. Experimental neurology 276, 31-40.

Mitsui, T., Shumsky, J.S., Lepore, A.C., Murray, M., Fischer, I., 2005. Transplantation of neuronal and glial restricted precursors into contused spinal cord improves bladder and motor functions, decreases thermal hypersensitivity, and modifies intraspinal circuitry. J Neurosci 25, 9624-9636.

Mligiliche, N.L., Xu, Y., Matsumoto, N., Idel, C., 2005. Survival of neural progenitor cells from the subventricular zone of the adult rat after transplantation into the host spinal cord of the same strain of adult rat. Anatomical science international 80, 229-234. 
Nantwi, K., El-Bohy, A., Schrimsher, G.W., Reier, P.J., Goshgarian, H.G., 1999. Spontaneous recovery in a paralyzed hemidiaphragm following upper cervical spinal cord injury in adult rats. Neurorehabil. Neural Repair 13, 225-234.

Nantwi, K.D., El-Bohy, A., Goshgarian, H.G., 1996. Actions of systemic theophylline on hemidiaphragmatic recovery in rats following cervical spinal cord hemisection. Experimental neurology 140, 53-59.

Nantwi, K.D., Goshgarian, H.G., 1998. Theophylline-induced recovery in a hemidiaphragm paralyzed by hemisection in rats: contribution of adenosine receptors. Neuropharmacology 37, 113-121.

Navarrete-Opazo, A., Vinit, S., Dougherty, B.J., Mitchell, G.S., 2015. Daily acute intermittent hypoxia elicits functional recovery of diaphragm and inspiratory intercostal muscle activity after acute cervical spinal injury. Experimental neurology 266, 1-10.

Nichols, N.L., Mitchell, G.S., 2015. Quantitative assessment of integrated phrenic nerve activity. Respiratory physiology \& neurobiology.

Oka, S., Honmou, O., Akiyama, Y., Sasaki, M., Houkin, K., Hashi, K., Kocsis, J.D., 2004. Autologous transplantation of expanded neural precursor cells into the demyelinated monkey spinal cord. Brain research 1030, 94-102.

Pfeifer, K., Vroemen, M., Blesch, A., Weidner, N., 2004. Adult neural progenitor cells provide a permissive guiding substrate for corticospinal axon growth following spinal cord injury. The European journal of neuroscience 20, 1695-1704.

Pitts, R.F., 1940. The respiratory center and its descending pathways. J. Comp. Neurol. 73, 605-625. Reier, P.J., 2004. Cellular transplantation strategies for spinal cord injury and translational neurobiology. NeuroRx 1, 424-451.

Ross, H.H., Rahman, M., Levkoff, L.H., Millette, S., Martin-Carreras, T., Dunbar, E.M., Reynolds, B.A., Laywell, E.D., 2011. Ethynyldeoxyuridine (EdU) suppresses in vitro population expansion and in vivo tumor progression of human glioblastoma cells. Journal of neuro-oncology 105, 485-498.

Ross, H.H., Sandhu, M.S., Cheung, T.F., Fitzpatrick, G.M., Sher, W.J., Tiemeier, A.J., Laywell, E.D., Fuller, D.D., 2012. In vivo intermittent hypoxia elicits enhanced expansion and neuronal differentiation in cultured neural progenitors. Experimental neurology 235, 238-245.

Sandhu, M.S., Dougherty, B.J., Lane, M.A., Bolser, D.C., Kirkwood, P.A., Reier, P.J., Fuller, D.D., 2009. Respiratory recovery following high cervical hemisection. Respiratory physiology \& neurobiology 169 , 94-101.

Sandhu, M.S., Lee, K.Z., Fregosi, R.F., Fuller, D.D., 2010. Phrenicotomy alters phrenic long-term facilitation following intermittent hypoxia in anesthetized rats. J Appl Physiol 109, 279-287.

Satkunendrarajah, K., Nassiri, F., Karadimas, S.K., Lip, A., Yao, G., Fehlings, M.G., 2016. Riluzole promotes motor and respiratory recovery associated with enhanced neuronal survival and function following high cervical spinal hemisection. Experimental neurology 276, 59-71.

Shin, J.C., Kim, K.N., Yoo, J., Kim, I.S., Yun, S., Lee, H., Jung, K., Hwang, K., Kim, M., Lee, I.S., Shin, J.E., Park, K.I., 2015. Clinical Trial of Human Fetal Brain-Derived Neural Stem/Progenitor Cell Transplantation in Patients with Traumatic Cervical Spinal Cord Injury. Neural plasticity 2015, 630932.

Snyder, E.Y., Teng, Y.D., 2012. Stem cells and spinal cord repair. N Engl J Med 366, 1940-1942. Vroemen, M., Aigner, L., Winkler, J., Weidner, N., 2003. Adult neural progenitor cell grafts survive after acute spinal cord injury and integrate along axonal pathways. The European journal of neuroscience 18, 743-751.

White, T.E., Lane, M.A., Sandhu, M.S., O'Steen, B.E., Fuller, D.D., Reier, P.J., 2010. Neuronal progenitor transplantation and respiratory outcomes following upper cervical spinal cord injury in adult rats.

Experimental neurology 225, 231-236.

Xing, Y.L., Roth, P.T., Stratton, J.A., Chuang, B.H., Danne, J., Ellis, S.L., Ng, S.W., Kilpatrick, T.J., Merson, T.D., 2014. Adult neural precursor cells from the subventricular zone contribute significantly to 
oligodendrocyte regeneration and remyelination. The Journal of neuroscience : the official journal of the Society for Neuroscience 34, 14128-14146.

Yang, H.Y., Lieska, N., Shao, D., Kriho, V., Pappas, G.D., 1993. Immunotyping of radial glia and their glial derivatives during development of the rat spinal cord. Journal of neurocytology 22, 558-571.

Yuan, X.B., Jin, Y., Haas, C., Yao, L., Hayakawa, K., Wang, Y., Wang, C., Fischer, I., 2016. Guiding migration of transplanted glial progenitor cells in the injured spinal cord. Scientific reports 6, 22576.

Zhang, H.T., Cheng, H.Y., Cai, Y.Q., Ma, X., Liu, W.P., Yan, Z.J., Jiang, X.D., Xu, R.X., 2009. Comparison of adult neurospheres derived from different origins for treatment of rat spinal cord injury. Neurosci Lett 458, 116-121.

Zhou, S.Y., Basura, G.J., Goshgarian, H.G., 2001. Serotonin(2) receptors mediate respiratory recovery after cervical spinal cord hemisection in adult rats. Journal of applied physiology 91, 2665-2673.

Zhou, S.Y., Goshgarian, H.G., 2000. 5-Hydroxytryptophan-induced respiratory recovery after cervical spinal cord hemisection in rats. Journal of applied physiology 89, 1528-1536.

Ziv, Y., Avidan, H., Pluchino, S., Martino, G., Schwartz, M., 2006. Synergy between immune cells and adult neural stem/progenitor cells promotes functional recovery from spinal cord injury. Proceedings of the National Academy of Sciences of the United States of America 103, 13174-13179. 


\begin{tabular}{lclll}
\hline Group & Variable & Baseline & Hypoxia & Post-hypoxia \\
\hline NPC & MAP & $100 \pm 6$ & $67 \pm 6^{*}$ & $102 \pm 6$ \\
Control & $(\mathrm{mmHg})$ & $97 \pm 4$ & $70 \pm 5^{\star}$ & $109 \pm 4^{*}$ \\
\hline $\mathrm{NPC}$ & $\mathrm{PaCO}_{2}$ & $41 \pm 2$ & $39 \pm 2$ & $42 \pm 2$ \\
Control & $(\mathrm{mmHg})$ & $45 \pm 2$ & $44 \pm 2$ & $48 \pm 2^{*}$ \\
\hline NPC & $\mathrm{PaO}_{2}$ & $154 \pm 9$ & $37 \pm 2^{\star}$ & $118 \pm 3^{*}$ \\
Control & $(\mathrm{mmHg})$ & $143 \pm 9$ & $32 \pm 1^{*}$ & $105 \pm 4^{*}$ \\
\hline NPC & $\mathrm{pH}$ & $7.32 \pm 0.01$ & $7.32 \pm 0.01$ & $7.29 \pm 0.01^{*}$ \\
Control & & $7.32 \pm 0.01$ & $7.30 \pm 0.01$ & $7.28 \pm 0.02^{*}$ \\
\hline
\end{tabular}

Table 1. Mean arterial blood pressure (MAP), partial pressure of arterial carbon dioxide $\left(\mathrm{PaCO}_{2}\right)$, oxygen $\left(\mathrm{PaO}_{2}\right)$, and arterial $\mathrm{pH}$ during baseline, hypoxia, and 6 min post-hypoxia. ${ }^{*}, \mathrm{p}$ $<0.05$ relative to baseline. 


\begin{tabular}{|cc|c|c|c|c|c|}
\hline \multicolumn{2}{|c|}{ Group } & Variable & Value & Treat- & Time & $\begin{array}{c}\text { Treat- } \\
\text { ment } \\
\text { ment }\end{array}$ \\
\hline \multirow{2}{*}{ Time }
\end{tabular}

Table 2. Respiratory variables measured using whole body plethysmography during normoxic "baseline" conditions. Data are provided for both the control (Con) and transplant groups (NPC), and include the breathing frequency $(\mathrm{Fb})$ inspiratory duration $(\mathrm{Ti})$, expiratory duration $(\mathrm{Te})$, inspiratory tidal volume (TV), minute ventilation (VE), peak inspiratory airflow (PIF) and peak expiratory airflow (PEF). The impact of respiratory challenge with hypoxia or hypercapnia on these variables is shown in Figure 4. The results of the two way repeated measures ANOVA are provided including the treatment effect (Con vs. NPC), time effect (4 vs. 8 wks), and the treatment $x$ time interaction. 


\begin{tabular}{|c|c|c|c|c|c|c|}
\hline \multicolumn{2}{|c|}{ Group } & Variable & Value & $\begin{array}{l}\text { Treat- } \\
\text { ment }\end{array}$ & Time & $\begin{array}{c}\text { Treat- } \\
\text { ment } x \\
\text { Time }\end{array}$ \\
\hline $\begin{array}{l}4 w k \\
8 w k\end{array}$ & $\begin{array}{l}\text { Con } \\
\text { NPC } \\
\text { Con } \\
\text { NPC }\end{array}$ & $\mathrm{Ti}(\mathrm{sec})$ & $\begin{array}{c}0.170 \pm 0.032 \\
0.179 \pm 0.029 \\
0.156 \pm 0.023 \\
* * 0.189 \pm 0.023\end{array}$ & 0.055 & 0.842 & 0.011 \\
\hline $\begin{array}{l}4 w k \\
8 w k\end{array}$ & $\begin{array}{l}\text { Con } \\
\text { NPC } \\
\text { Con } \\
\text { NPC }\end{array}$ & $\mathrm{Te}(\mathrm{sec})$ & $\begin{array}{c}0.313 \pm 0.062 \\
0.309 \pm 0.059 \\
0.281 \pm 0.068 \\
{ }^{*} 0.348 \pm 0.083\end{array}$ & 0.325 & 0.346 & 0.009 \\
\hline $\begin{array}{l}4 w k \\
8 w k\end{array}$ & $\begin{array}{l}\text { Con } \\
\text { NPC } \\
\text { Con } \\
\text { NPC }\end{array}$ & $\mathrm{VE}(\mathrm{ml} / \mathrm{min})$ & $\begin{array}{l}353 \pm 88 \\
399 \pm 61 \\
416 \pm 62 \\
386 \pm 76\end{array}$ & 0.503 & 0.203 & 0.119 \\
\hline $\begin{array}{l}4 w k \\
8 w k\end{array}$ & $\begin{array}{l}\text { Con } \\
\text { NPC } \\
\text { Con } \\
\text { NPC }\end{array}$ & $\operatorname{VE}\left({ }^{*} 100 g^{-1}\right)$ & $\begin{array}{l}137 \pm 35 \\
148 \pm 24 \\
154 \pm 17 \\
142 \pm 62\end{array}$ & 0.746 & 0.370 & 0.214 \\
\hline $\begin{array}{l}4 w k \\
8 w k\end{array}$ & $\begin{array}{l}\text { Con } \\
\text { NPC } \\
\text { Con } \\
\text { NPC }\end{array}$ & $\mathrm{PIF}$ (ml/sec) & $\begin{array}{l}24.0 \pm 5.8 \\
26.2 \pm 3.7 \\
27.5 \pm 3.3 \\
26.2 \pm 3.4\end{array}$ & 0.607 & 0.087 & 0.182 \\
\hline $\begin{array}{l}4 w k \\
8 w k\end{array}$ & $\begin{array}{l}\text { Con } \\
\text { NPC } \\
\text { Con } \\
\text { NPC }\end{array}$ & $\mathrm{PEF}(\mathrm{ml} / \mathrm{sec})$ & $\begin{array}{l}17.0 \pm 3.5 \\
18.5 \pm 3.1 \\
19.5 \pm 2.3 \\
18.8 \pm 2.3\end{array}$ & 0.441 & 0.149 & 0.300 \\
\hline
\end{tabular}

Table 3. Respiratory variables measured using whole body plethysmography during a brief hypoxic respiratory challenge. Data are provided for both the control (Con) and transplant groups (NPC), and include the inspiratory duration (Ti), expiratory duration $(\mathrm{Te})$, minute ventilation $(\mathrm{VE})$, peak inspiratory airflow (PIF) and peak expiratory airflow (PEF). The tidal volume and breathing frequency data are shown in Figure 4 . The results of the two way repeated measures ANOVA are provided including the treatment effect (Con vS. NPC), time effect (4 vs. 8 wks), and the treatment $x$ time interaction. ${ }^{* *}$ indicates $p<0.05$ vs. CON at 8 wks; ${ }^{*}$ indicates $\mathrm{p}<0.05 \mathrm{vs}$. NPC at 4 wks 


\begin{tabular}{|c|c|c|c|c|c|c|}
\hline \multicolumn{2}{|c|}{ Group } & \multirow{2}{*}{$\begin{array}{l}\text { Variable } \\
\text { Ti (sec) }\end{array}$} & \multirow{2}{*}{$\begin{array}{c}\text { Value } \\
\\
0.169 \pm 0.037 \\
0.165 \pm 0.033 \\
0.149 \pm 0.034 \\
0.177 \pm 0.037\end{array}$} & \multirow{2}{*}{$\begin{array}{l}\text { Treat- } \\
\text { ment } \\
0.306\end{array}$} & \multirow{2}{*}{$\begin{array}{l}\text { Time } \\
0.672\end{array}$} & \multirow{2}{*}{$\begin{array}{c}\text { Treat- } \\
\text { ment } \\
x \\
\text { Time } \\
0.044\end{array}$} \\
\hline $\begin{array}{l}4 w k \\
8 w k\end{array}$ & $\begin{array}{l}\text { Con } \\
\text { NPC } \\
\text { Con } \\
\text { NPC }\end{array}$ & & & & & \\
\hline $\begin{array}{l}4 w k \\
8 w k\end{array}$ & $\begin{array}{l}\text { Con } \\
\text { NPC } \\
\text { Con } \\
\text { NPC }\end{array}$ & $\mathrm{Te}(\mathrm{sec})$ & $\begin{array}{l}0.228 \pm 0.060 \\
0.236 \pm 0.060 \\
0.199 \pm 0.052 \\
0.253 \pm 0.067\end{array}$ & 0.143 & 0.636 & 0.100 \\
\hline $\begin{array}{l}4 w k \\
8 w k\end{array}$ & $\begin{array}{l}\text { Con } \\
\text { NPC } \\
\text { Con } \\
\text { NPC }\end{array}$ & VE (ml/min) & $\begin{array}{l}493 \pm 173 \\
538 \pm 120 \\
561 \pm 121 \\
508 \pm 141\end{array}$ & 0.300 & 0.242 & 0.301 \\
\hline $\begin{array}{l}4 w k \\
8 w k\end{array}$ & $\begin{array}{l}\text { Con } \\
\text { NPC } \\
\text { Con } \\
\text { NPC }\end{array}$ & $\operatorname{VE}\left({ }^{*} 100 \mathrm{~g}^{-1}\right)$ & $\begin{array}{l}190 \pm 63 \\
200 \pm 46 \\
209 \pm 45 \\
187 \pm 51\end{array}$ & 0.809 & 0.679 & 0.268 \\
\hline $\begin{array}{l}4 w k \\
8 w k\end{array}$ & $\begin{array}{l}\text { Con } \\
\text { NPC } \\
\text { Con } \\
\text { NPC }\end{array}$ & $\mathrm{PIF}(\mathrm{ml} / \mathrm{sec})$ & $\begin{array}{l}26.6 \pm 2.6 \\
30.5 \pm 1.7 \\
30.7 \pm 6.5 \\
28.8 \pm 7.1\end{array}$ & 0.600 & 0.373 & 0.123 \\
\hline $\begin{array}{l}4 w k \\
8 w k\end{array}$ & $\begin{array}{l}\text { Con } \\
\text { NPC } \\
\text { Con } \\
\text { NPC }\end{array}$ & $\mathrm{PEF}(\mathrm{ml} / \mathrm{sec})$ & $\begin{array}{l}23.1 \pm 2.0 \\
25.0 \pm 1.2 \\
24.7 \pm 4.6 \\
23.3 \pm 5.7\end{array}$ & 0.799 & 0.934 & 0.312 \\
\hline
\end{tabular}

Table 4. Respiratory variables measured using whole body plethysmography during a brief hypercapnic respiratory challenge. Data are provided for both the control (Con) and transplant groups (NPC), and include the inspiratory duration (Ti), expiratory duration (Te), minute ventilation (VE), peak inspiratory airflow (PIF) and peak expiratory airflow (PEF). The tidal volume and breathing frequency data are shown in Figure 4. The results of the two way repeated measures ANOVA are provided including the treatment effect (Con vs. NPC), time effect (4 vs. 8 wks), and the treatment $x$ time interaction. 

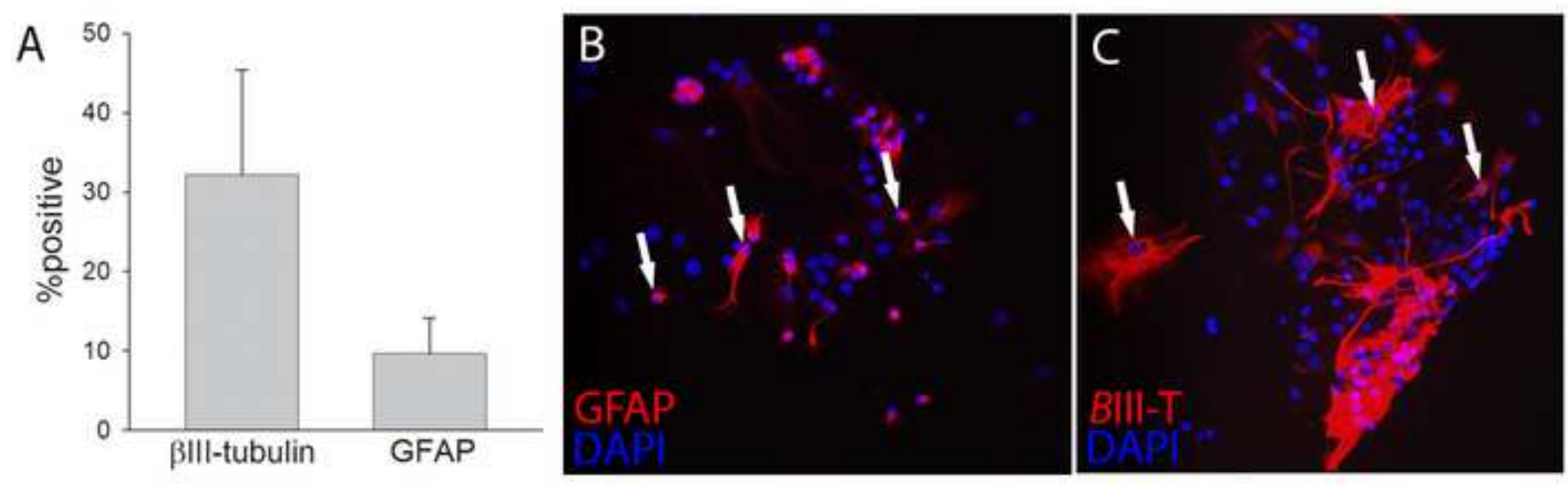

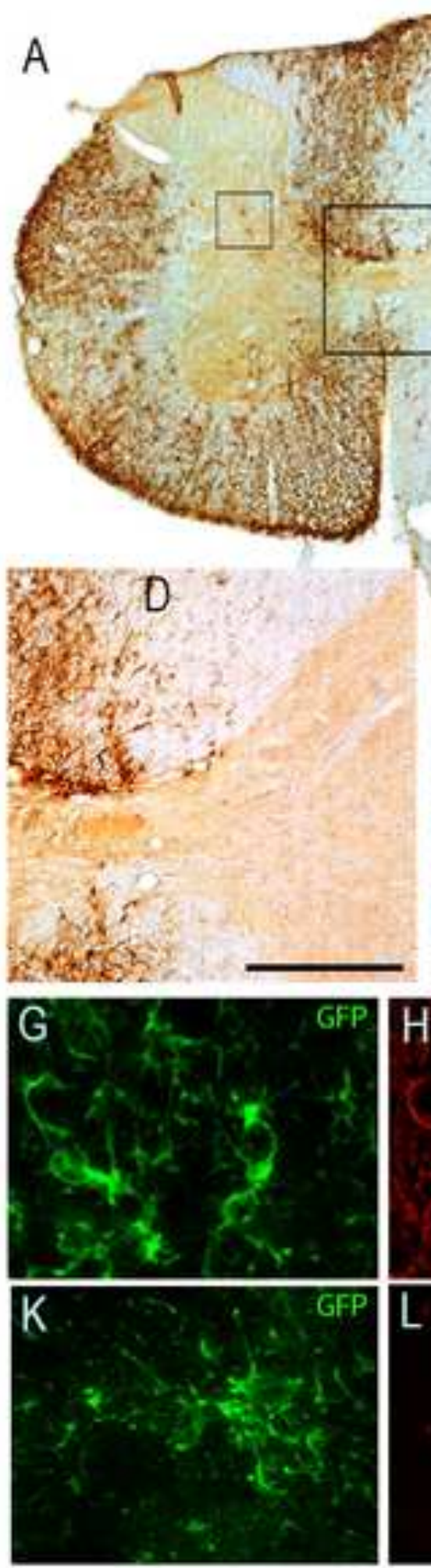
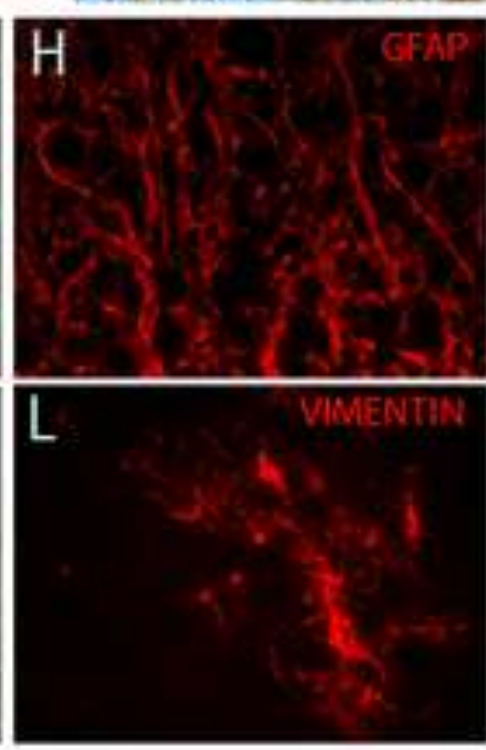
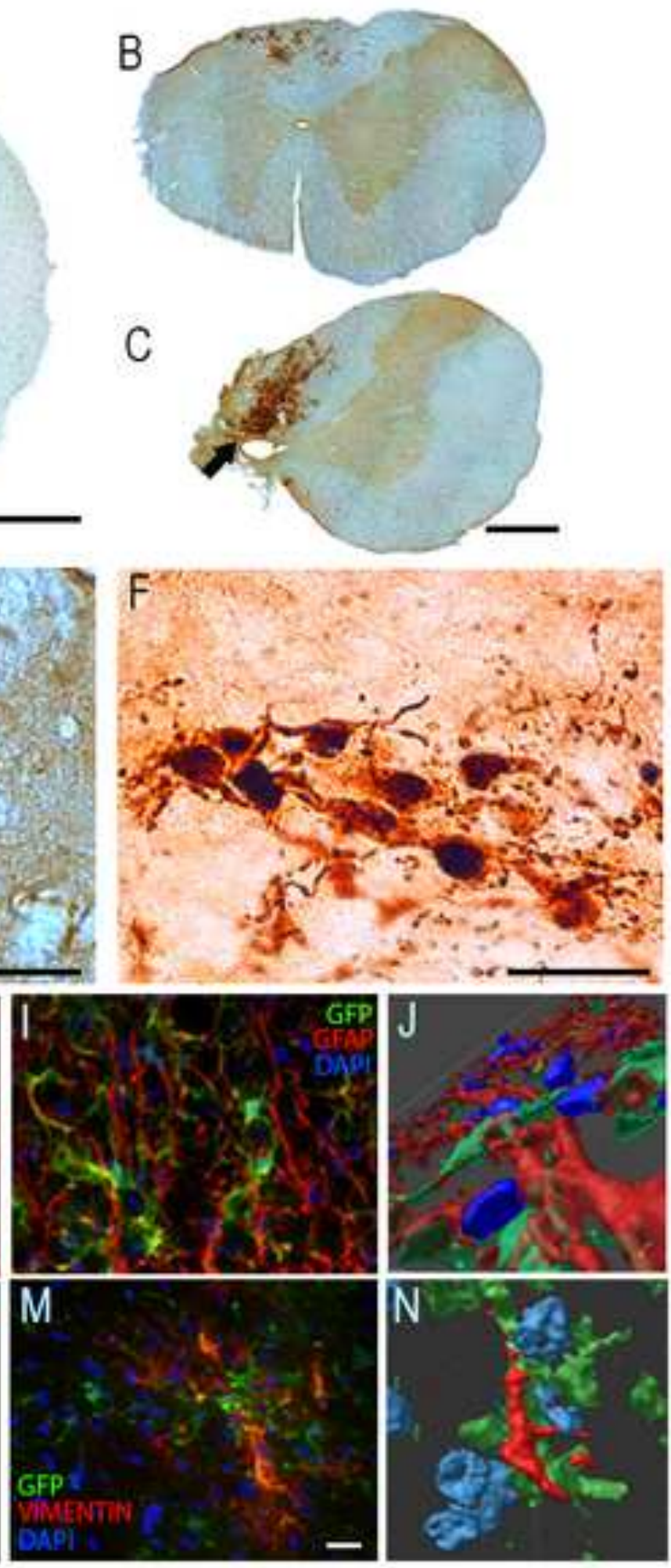

\section{Figure 2}

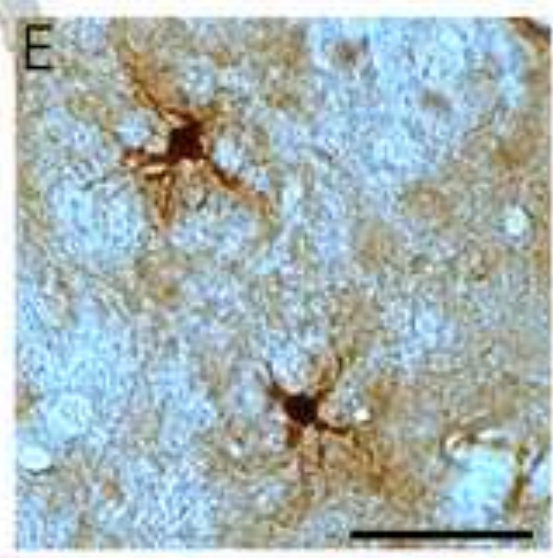



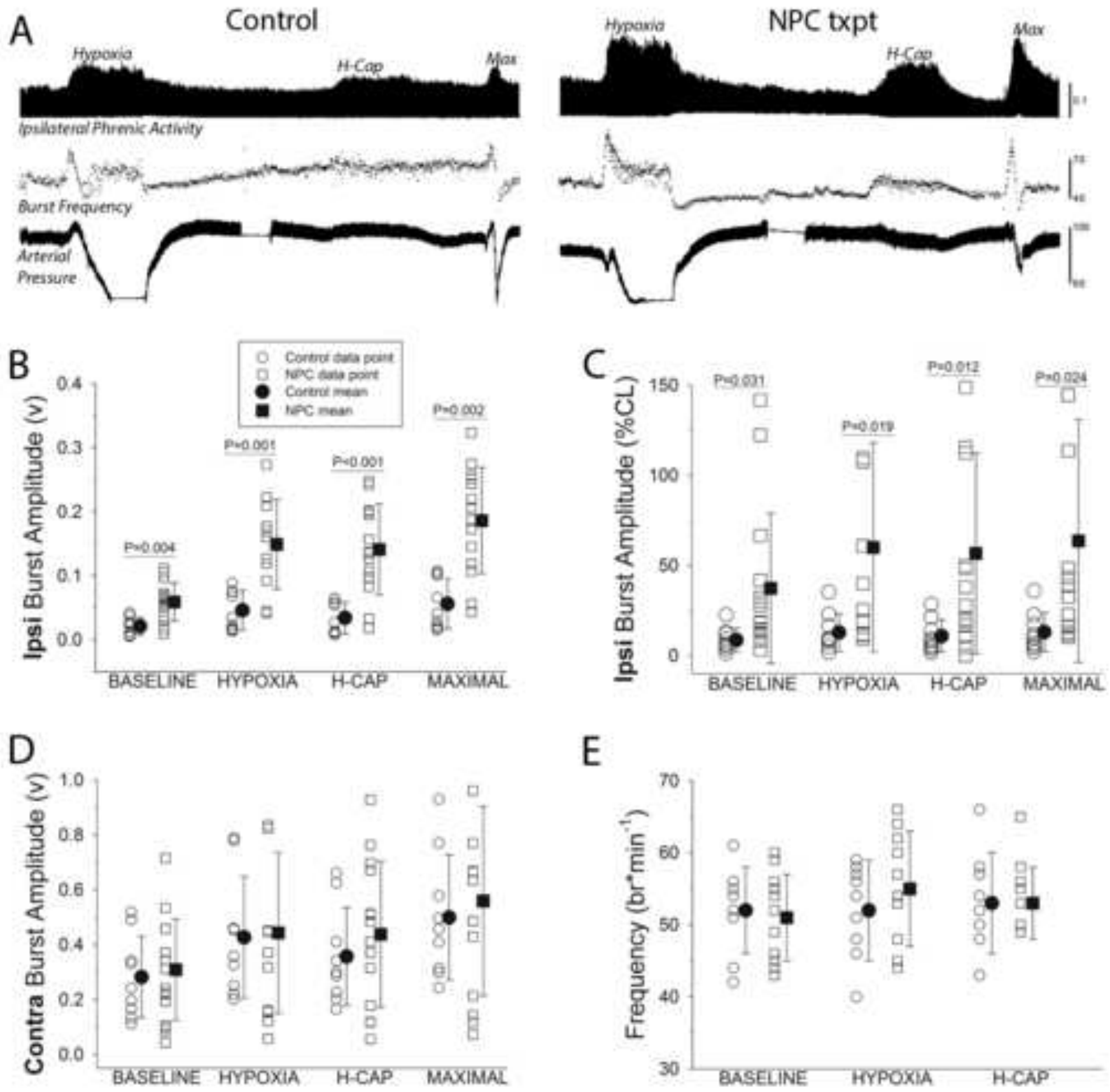

E

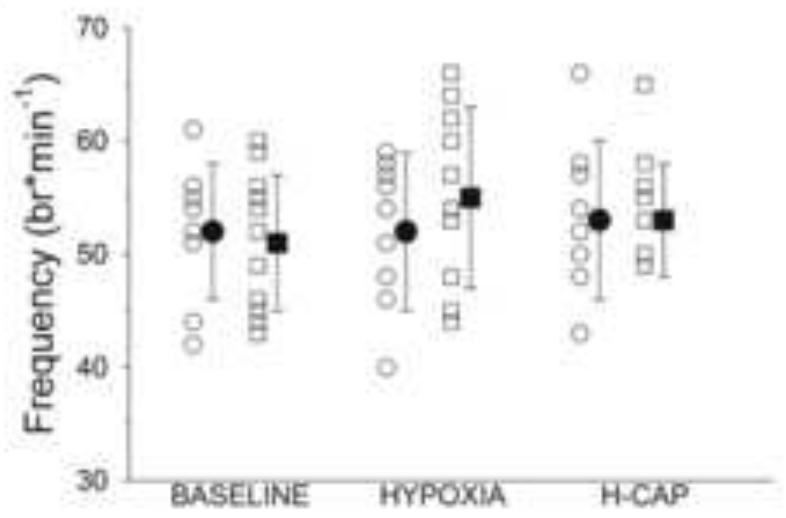


A Baseline NPC txpt

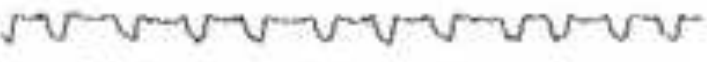

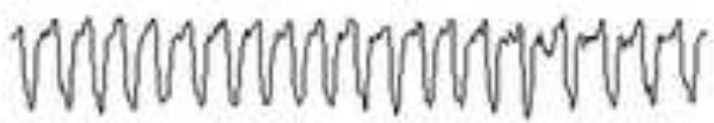
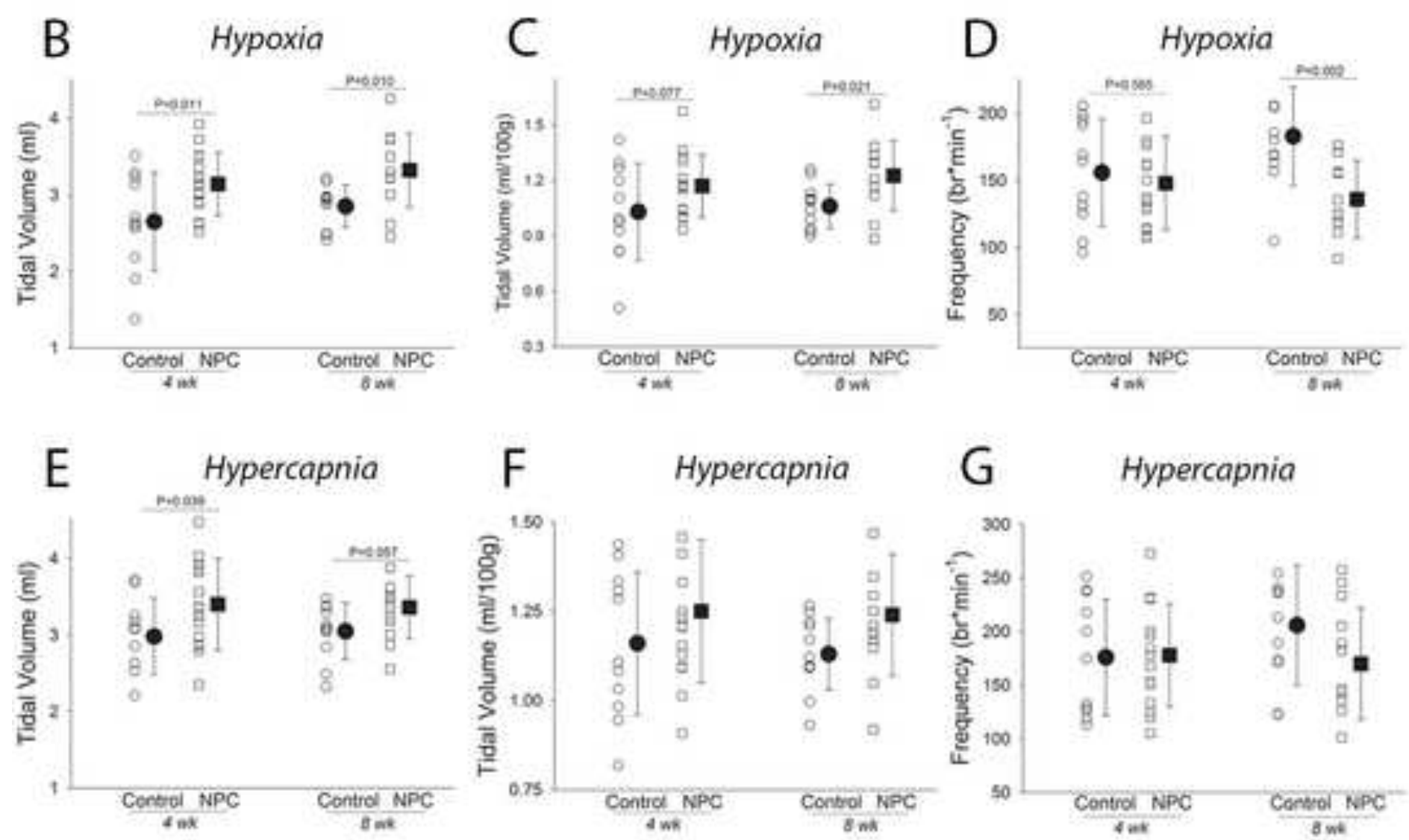

G

Hypercapnia

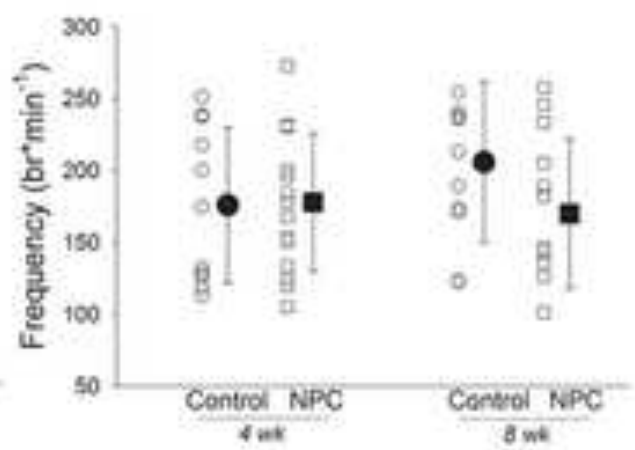

